\title{
PSEUDO AINHUM - A PROSPECTIVE STUDY
}

\author{
Dr. Rehan e Kibria ${ }^{1}$
}

1. Surgical Specialist PNS Shifa Hospital, Karachi
Correspondence Address:

Dr. Rehan e Kibria

Surgical Specialist

PNS Shifa Hospital, Karachi

rehankibria@yahoo.com
Article received on:

09/12/2012

Accepted for Publication:

01/10/2013

Received after proof reading:

26/01/2014

\section{INTRODUCTION}

The syndrome embraces a group of abnormalities which occur in a variety of combinations, mainly effecting the limbs and rarely the trunk. It is characterized with fibrous bands that encircle, strangulate and even amputate some parts of the fetus. The disorder is typically characterized with continuous progression and deepening of fibrous rings ultimately resulting in aseptic, ischemic amputation of the effected part. Patterson ${ }^{1}$ classified the varieties of disorder as follows: (a) Simple constriction rings (b) Constriction ring accompanied by deformity of the distal part, with or without lymphoedema.(c) Constriction ring accompanied by fusion of distal parts ranging

\begin{abstract}
ABSTRACT... Background: Amniotic band syndrome also known as ADAM complex, amniotic band sequence, congenital constrictions, bands and Pseudo Ainhum is a congenital disorder caused by entrapment of fetal parts (usually a limb or digits) in fibrous amniotic bands while in utero. Syndrome which is featured by one or more characteristic fibrous bands that encircle, deepen, strangulate and amputate parts of the human body. It start in a fetus \& continues throughout life if not checked and treated. It is not an uncommon condition in our country but

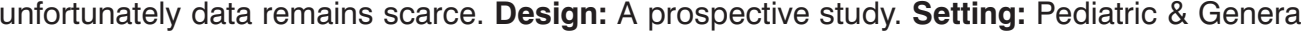
Surgical Department of CMH Multan. Period: June 2010 to June 2012. Materials and methods: Characteristic progressive constriction band was undertaken. The patients were examined Clinically and findings recorded. An X-ray to rule out underlying bone anomaly was done. Treat required multiple staged procedures. Correction of the constriction ring was done by excision and Z-plasty to prevent or alleviate lymphoedema, separation of distally fused digits and skin grafting of defect. Results: Fifteen patients comprising of ten male \& five females were seen. Age of presentation ranged from second week of life to 12 years with mean age of 14 months. A total of twenty one limbs and one penile shaft were effected. These included two right upper limbs, three left upper limbs, ten right lower limbs and six left lower limbs. Penile shaft of one of the patients just short of glans was involved. Four main types of lesions were found which comprised of constriction rings, intra uterine amputations, acrosyndactyl and simple syndactyl. Conclusions: Pseudo Ainhum is a disease of unknown etiolgy \& could cause morbidity in new Early surgery is required for successful outcome.
\end{abstract}

Key words: Pseudo Ainhum, Acrosyndactyl, amputation, constriction bands.

Article Citation: Rehan e Kibria. Pseudo Ainhum - a prospective study. Professional Med $J$ 2014;21(1): 044-048.

from mild to gross acrosyndactyl and (d) Intra uterine amputations.

According to patterson ${ }^{2}$ the diagnosis of this syndrome in a patient must have two or more features from the above. The deformities are the results of a cascade of events that follow an intra uterine disruption ${ }^{3}$. The etiology of this disease is not known . three main theories attempt to explain the specific cause of disruption, (a) Intrinsic Theory $^{4}$ (b) Extrinsic theory ${ }^{5}$ (c) Intra uterine trauma theory ${ }^{6}$. Condition although not uncommon has scanty data available. 


\section{MATERIAL AND METHODS}

Based on Patterson's Classification patients presenting two or more of the characteristic features were entered into the study. Patients with congenital amputations were entered into the study if they were transverse. Ray amputations along with classic ainhum (band around little toe) were excluded from the study unless they had other features of the syndrome.

The study began in June 2010 at the General \& Pediatric surgical unit of $\mathrm{CMH}$ Multan where two patients were initially seen and treatment started in the form of staged excision and Z-plasties which continued till june 2012 along with constant addition to the list of the patients fulfilling the afore mentioned criteria . A total of 15 patients including ten male and five female patients were selected for the study. The patients underwent a complete clinical examination. A complete family history, pregnancy history including information regarding medical illness, medications, alcohol, smoking and substance abuse, onset and vigour of fetal movement, delivery and neonatal adaptations were taken. The site of malformation and degree of internal or external anomalies were recorded. Xrays of the affected limbs in AP \& lateral positions were taken.

All patients had preoperative and postoperative photographs taken. Surgical procedures performed included excision of the constricting ring followed by Z- plasty usually done with in 02 weeks of reporting of the patients after preliminary examination and clinical tests for evaluation and fitness. Patients with acrosyndactyl had their fingers separated, the site of separation was either grafted or allowed to heal secondarily. Most of the staged procedures were performed with in intervals of three months.

One patient with constriction ring at the distal shaft of penis with swelling at glans reported at a late stage at the age of 12 . Staged Z- plasty for ventrum has been done and the deep fissure on dorsum scheduled for latter.

\section{RESULTS}

There were 15 patients in all with 21 affected limbs. Sex ratio was male: female 2:1 including 10 males and 5 females. Age at presentation ranged from 14 days to 12 years with a mean age of 14.6 months. Affected limbs included Right upper limbs(2), Left upper $\operatorname{limbs}(3)$, Right lower limbs(10) and left lower limbs(6) in addition to shaft penis (1). There was no family history of constriction rings in any patient.

In the upper limbs 43 digits were involved. The hand, forearm and upper arm were not involved in any case. In the lower limbs 38 toes were involved along with various parts of limb. Foot was involved once, the leg five times, the thigh once, the lower leg nine times along with the shaft of penis once. Constriction rings involved 12 sites in the lower limbs and 5 sites in the upper limbs. In the upper limbs only the digits were involved namely the thumb(1), index finger (1), middle finger (1) and ring finger (2). The little finger was always spared. In the lower limb constriction ring sites included thigh (10), distal third of leg(9), the foot(1) and toes (5).

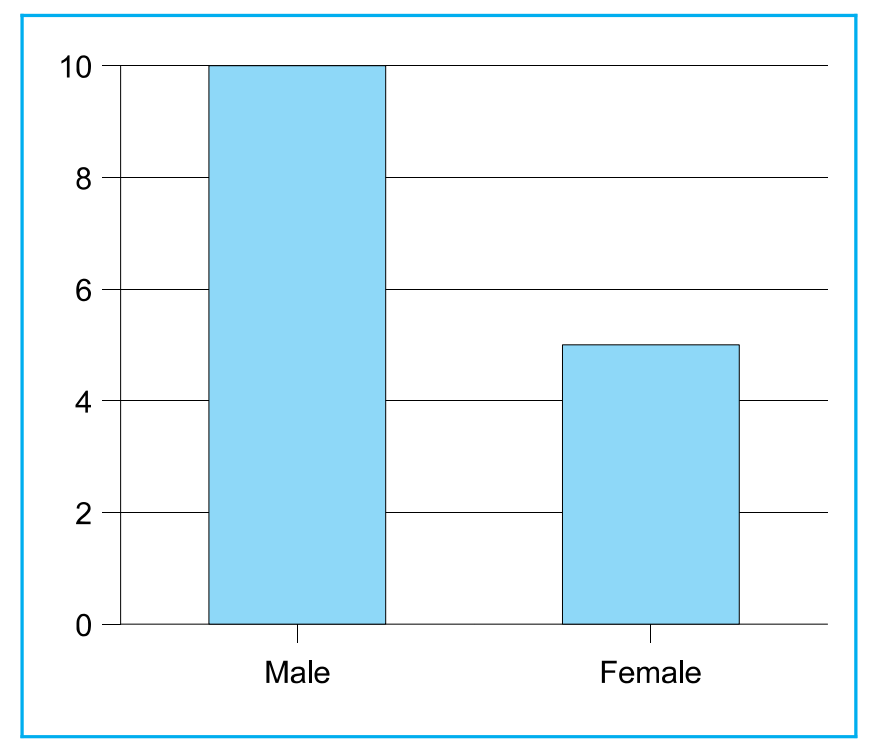

Intrauterine amputations involved the digits of both upper and lower limbs. In the upper limb there were 13 amputations involving thumbs(3), index finger (3), middle finger (4) and ring finger (3). No amputation in little finger was detected. In the foot the involved digits included great toe(3), 


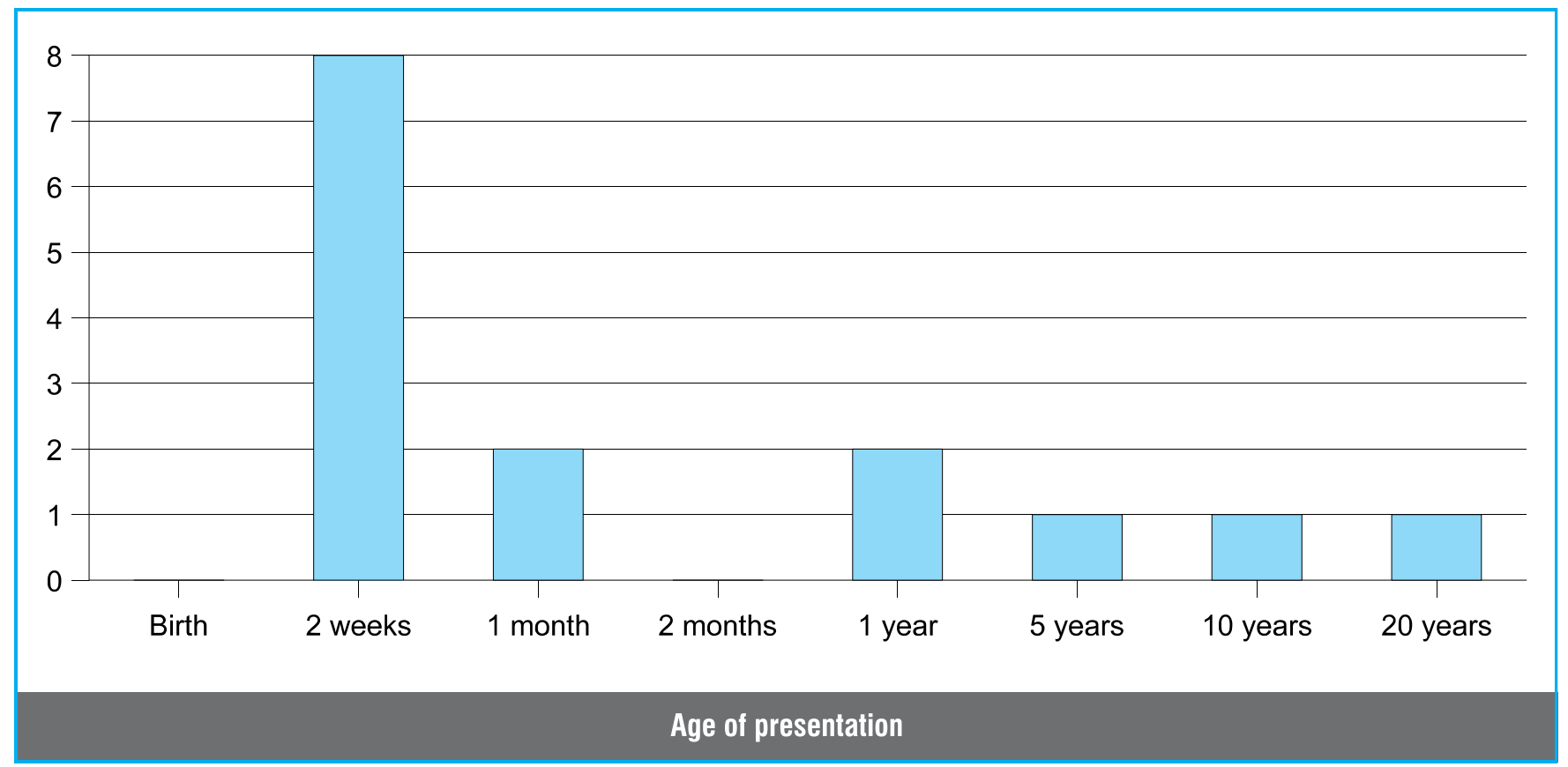

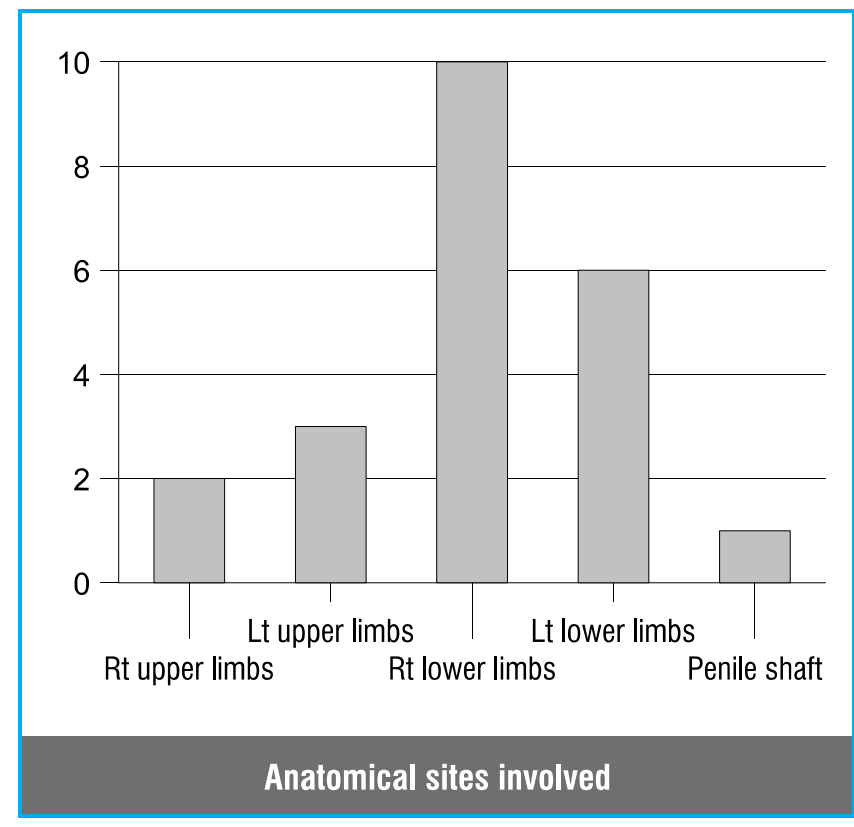

second toe and little toe(2)each and (1) each from third and fourth toes. Associated anomalies included lymphoedema of foot and ankle distal to constriction ring in 16 of 17 lower limb patients. One case of cleft right lip and cleft soft palate was also discovered.

There were 10 cases of acrosyndactyl involving eight hands and four feet. In the hand digital involvement was as follows, three thumbs, six index and middle fingers each and five rings fingers. Three little fingers were also involved. Two cases of simple syndactyl were found involving index, middle \& ring fingers of one hand and second third and fourth toe of one foot.

Effected limbs were treated surgically and a total of 40 procedures were carried out and (a) excision of constriction rings with (b) Z- plasty(22) (c) release of syndactyl(2) (d) release of acrosyndactyl (10) (e) grafting defect(5) (f) clift lip and palate(1) repair were done.

\section{DISCUSSION}

The incidence of constriction ring syndrome varies from 1 in 1500 to 15,000 live births. There is no known racial predilection and the male preponderance is in concurrence with other reports ${ }^{1}$. Familial occurrence if any is rare and it is believed there is no genetic predisposition ${ }^{3}$.

Pseudo Ainhum or congenital constriction ring syndrome occurs when deep cutaneous creases encircle a limb as if a string were tied tightly around it. Its frequent association with congenital amputations and acrosyndactyl led this malformation to be designated as a syndrome. Other terms in literature for this condition include Annular band syndrome, streeter dysplasia, 


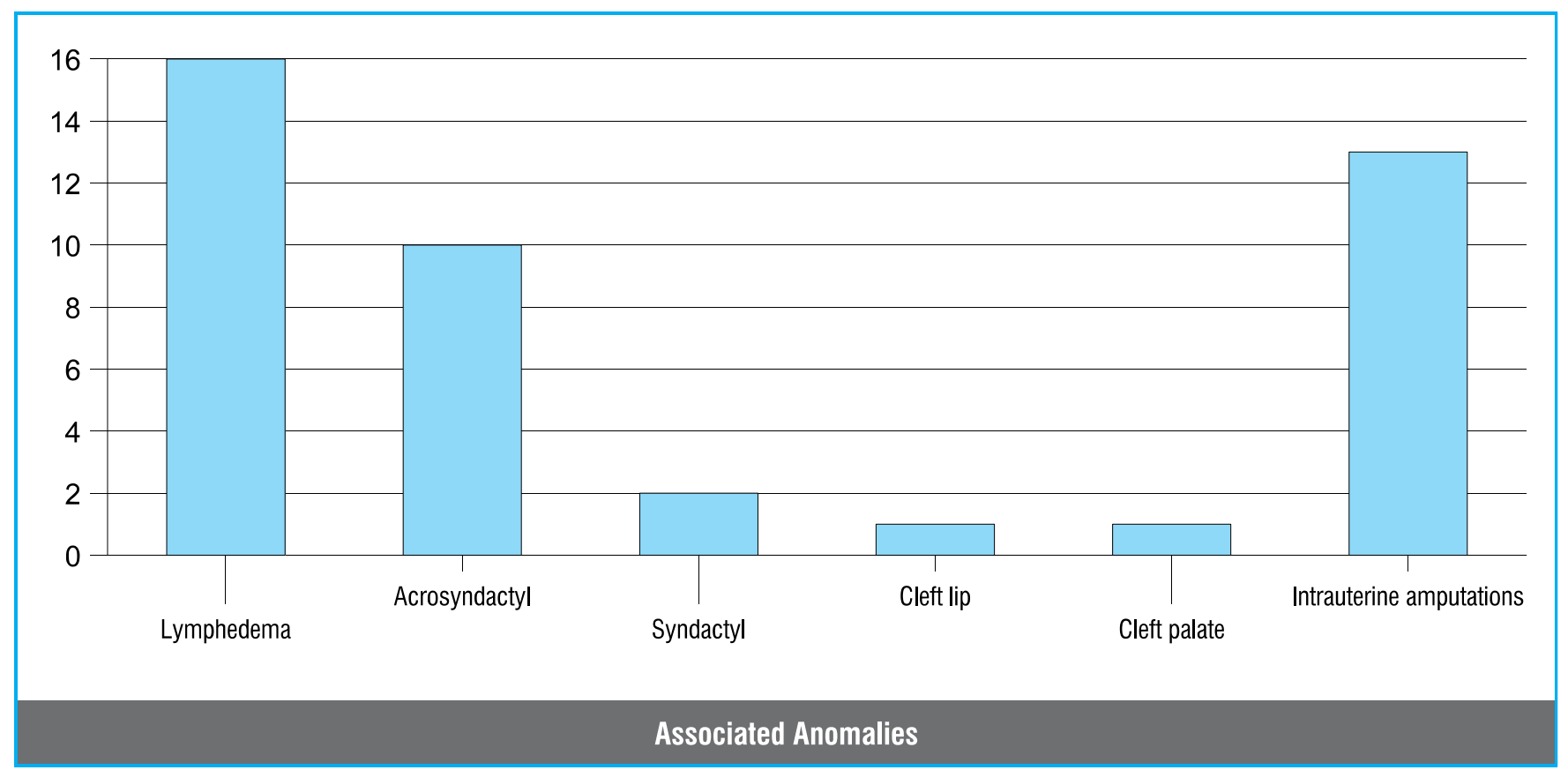

Congenital amputations and fenestrated syndactyl ${ }^{7}$.

The first recorded case in history was by Montgomery in 1832 who described an aborted fetus with fibrous bands passing from both hands to legs and wound around deep grooves in limbs. Whether these amputations and rings constriction were due to amniotic bands or due to developmental dysplasia remains controversial.

Although the pathogenesis for this disorder is uncertain but a number of theories have sprung to suggest the etiology. The Intrinsic ${ }^{4}$ Theory is the earliest and it states that these deformities were the result of a "defective germ plasm" within the embryo. Streeter ${ }^{4}$ believed that the bands represented macerated sheets of epidermis and the residual defective local tissue. This theory is supported by localized areas of involvement within the limb and presence of systemic and internal visceral anomalies.

The second Extrinsic Theory was given by Torpin ${ }^{5}$. In it the mesodermic band causing strangulation and amputation occurred due to an early rupture of amnion. After rupture the amnion grows abnormally and seperates from chorion. The amniotic fluid escapes causing oligohydramnios.
The fetus leaves amniotic sac and lies next to chorion .Multiple mesodermic bands issuing from chorionic face of amnion strangulate the finger, limbs and cranium. Lack of familial incidence, transverse disposition of lesions, limitation to long digits/ limbs, delivery of amputated parts and absence of associated internal malformations support this theory.

The third Intrauterine Theory postulated by Kino ${ }^{6}$ believed that congenital constrictions, amputations and acrosyndactyl are caused by intrauterine trauma during pregnancy which disrupts blood supply to marginal sinuses of limb plate.

The number of associated anomalies in this report was lower than in other studies ${ }^{1,2}$. Other known malformations associated with this syndrome but not in our series include clubfoot, leg length discrepancy and bone anomalies. Surgical correction of constriction ring should aim at preventing or alleviating distal limphodema, separation of associated distal fusion and removal of unsightly groove for sake of cosmesis. Z plasty was the most effective procedure and yielded cosmetic results in our series. when intrauterine amputation of digits has occurred there may be opportunities to improve functions by transfer of 
finger stumps from one position to another, deepening of web spaces or free toe transfer. None of these were however done in our series.

\section{CONCLUSIONS}

It is thus concluded that congenital constriction ring syndrome is of uncertain etiology and could cause morbidity in new born. The syndrome and its complication are amenable to corrective surgery with good results. Early intervention is desirable for successful outcome.

Copyright@ $1^{\text {st }}$ Oct, 2013.

\section{REFERENCES}

1. Dossi llon D. Rembouts JJ, Verellen - Dumoulin $\mathrm{CH}$, Vanwigck $R$, Vincent $A$, etal. A congenital ring constriction syndrome of limbs: A report of 19 cases. Br J plast surg 1998:41:270-77.

2. Batterson TJ. Congenital ring constriction, $\mathrm{Br} . \mathrm{J}$ Plast Surg 1999;14:1-31.
3. Upton J3rd, Constriction ring syndrome in Mathes SJ, editor, Plastic Surgery vol 8. The hand and upper limbs, Part 2. Ed Herts, 2, ed. Philadelphin; Saunden Elsevier; 2002;P.185-213.

4. Treeter GL. Focal deficiencies in fetal tissues and their relation to intrautenine amputatios. Contributions Embryol 2003;22:1-4.

5. Jopkin R. Amniochorionic mesoblastic fibrous strings and amniotic hands: associated constricting fetal malformation and fetal death. Am Jobstet Gynaecol 2006;191:65-75.

6. Kino Y. Clinical and experimental studies of congenital constriction based syndrome, with an emphasis on its etiology. $J$ Bone and Surgery Am2009;57:636-43.

7. Kwane Nkrumah, Emanual JK, Charles Amen, Congenital constriction ring syndrome of limbs. A study . J. Pediatric Surg 2009;5:79-83.

\section{CORRECTION}

The amendment of the Professional Vol: 20, No.06 (Prof-2103) on page 931 is as under;

\section{INCORRECT}

$\begin{array}{ll}\text { 1. } & \text { DR. MALIK HUSSAIN JALBANI } \\ & \text { Professor of Urology } \\ & \text { SMBBMU, Larkana } \\ \text { 2. } & \text { DR. NISAR AHMED SHAIKH } \\ & \text { Assistant Professor of Urology } \\ & \text { SMBBMU, Larkana } \\ \text { D. GHULAM SHABIR SHAIKH } & \text { Associate Professor of Urology } \\ & \text { SMBBMU, Larkana }\end{array}$

\section{CORRECT}

1. DR. MALIK HUSSAIN JALBANI Professor of Urology SMBBMU, Larkana

2. DR. NISAR AHMED SHAIKH Assistant Professor of Urology SMBBMU, Larkana

3. DR. GHULAM SHABIR SHAIKH Assistant Professor of Pathology SMBBMU, Larkana

4. Dr. Akbar Ali Soomro Associate Professor of Pathology SMBBMU, Larkana 